\title{
O PALHAÇO, DE SELTON MELLO, E A DISCUSSÃO DO EU FRENTE À CONSTRUÇÃO DA NARRATIVA DO SUJEITO
}

\author{
THE CLOWN, BY SELTON MELO, AND THE DISCUSSION OF "ME" \\ DUE TO THE CONSTRUCTION OF SELF'S NARRATIVE
}

Vanessa Silva Andrade 1 Renato de Oliveira Dering 2

Recebido: 02 fev. 2019

Aceito: 16 mai. 2019

DOI https://doi.org/10.29327/2.1373.1-4

RESUMO: O presente estudo aborda uma reflexão sobre as possibilidades que o cinema traz na discussão acerca da identidade do sujeito. As identidades, ao longo de um processo evolutivo, mostraram-se instáveis, visto a evolução do mundo e as inúmeras possibilidades que ele trouxe. Observada tais proposições, tomou-se como escopo de análise o filme brasileiro O Palhaço (2011), de Selton Mello. A narrativa fílmica conta a história de Benjamin, um palhaço circense que, descontente com seu modo de vida e sem se encontrar como alguém da sociedade, busca uma nova identidade. Essa busca, no filme, é representada pela sua saída da trupe circense, pela expedição do documento físico de identidade e pelo anseio em comprar um ventilador. É nesse envolto que o trabalho discute as relações de construção de identidade do sujeito, pautado, principalmente, nos apontamentos de Bauman (2005) e Hall (2005; 2008).

PALAVRAS-CHAVE: Identidade; Narrativa fílmica; Cinema brasileiro

ABSTRACT: The present study approaches a reflection on the possibilities that the cinema brings in the discussion about the identity of the person. Identities, throughout an evolutionary process, have proved unstable, given the evolution of the world and the innumerable possibilities it has brought. Observed these propositions, the Brazilian film O Palhaço (2011), by Selton Mello was taken as the scope of analysis. The narrative film tells the story of Benjamin, a circus clown who,

\footnotetext{
${ }^{1}$ Graduanda em Artes Visuais pela Universidade Federal de Goiás (UFG). Docente no Colégio Lassale (CLG). E-mail: vanessa nb2@,hotmail.com ORCID iD https://orcid.org/0000-0001-5422-7276

2 Doutorando em Letras e Linguística pela Universidade Federal de Goiás (UFG). Docente no Centro Universitário de Goiás (Uni-ANHANGUERA). Líder do Grupo de Pesquisas FORPROLL/CNPq. E-mail: renatodering@,gmail.com ORCID iD https://orcid.org/0000-0002-0776-3436
} 
dissatisfied with his way of life and without meeting as a member of society, seeks a new identity. This quest, in the film, is represented by his departure from the circus troupe, the issuance of the physical identity document and the yearning to buy a fan. It is in this envelope that the work discusses the relations of construction of identity of the person, based mainly on the notes of Bauman (2005) and Hall (2005; 2008).

KEYWORDS: Identity; Film narrative; Brazilian cinema

\section{INTRODUÇÃO}

O cinema atinge hoje um patamar visionário que foi desejado desde a ampliação do mercado da área, no início do século XX. Entre sua criação, consolidação e fenômeno, percebe-se um mercado diverso e cheio de possibilidades. "É uma arte em movimento, uma arte apressada, uma arte em incessante solavanco e desordem, e isso, às vezes, leva o cineasta a ver mudanças profundas [...] [em suas mais variadas formas]" (CARRIÈRE, 2015, p. 20, acréscimo nosso). Assim também ocorreu na relação dessa arte com os processos educacionais, que, ao longo dos anos, pleiteou diálogos dos mais variados, ainda em constante construção.

Tem-se, então, que o estudo de produções cinematográficas foi algo que chamou a atenção de pesquisadores de diferentes áreas de estudo de tal forma que esses estudiosos buscam compreender as diversas formas de representação que a sétima arte pode oferecer em pontos ímpares da sociedade. A compreensão da História do Brasil, por exemplo, pode ser associada a muitos momentos do cinema nacional, como o Cinema Novo, que traz ponderações sobre igualdade social em um Brasil de instabilidades políticas.

O cinema contemporâneo, por sua vez, já busca "testar" novas formas para públicos distintos. Desde Central do Brasil, de Walter Salles, os filmes ganharam força narrativa para ousarem nas abordagens nos mais diferentes gêneros. A comédia escrachada é uma percursora, com nomes conhecidos pela grande população devido a sua visibilidade em canais abertos de grande audiência. Desses casos, destaca-se o comediante Leandro Hassum, que emplacou mais de 10 filmes na última década, com destaque para a sequência de películas Até que sorte nos separe (2012, 2013, 2015); a atriz Ingrid Guimarães, destaque também com a trilogia De pernas para o ar 
(2010, 2012, 2019); além do estrondoso sucesso bíblico Os dez mandamentos - o filme, produzido pela emissora Record, depois do sucesso de suas narrativas novelescas.

Em contrapartida a esses ápices, encontra-se algumas produções de figuras conhecidas da sociedade, mas que trazem em suas narrativas o "eu" entre os conflitos desse "eu" e desse "eu" com a sociedade. Destaca-se, assim, a produção artística de Selton Mello, que foge dos holofotes caricatos para um mergulho nos sujeitos. Assim foi com o sucesso fílmico-televisivo $O$ auto da compadecida (2000), em que deu vida a um dos protagonistas da obra literária de Ariano Suassuna; bem como foi com Benjamin, personagem do filme O palhaço (2011), foco deste estudo.

Investigar como o filme $O$ Palhaço (2011) traz reflexões sobre o processo de construção de identidades do sujeito e suas relações com o eu e a sociedade são objetivos deste estudo, que busca discutir como o entendimento das narrativas fílmicas pode nos servir como base para compreender a formação de identidades e seus diálogos possíveis.

\section{ENTRE AS PÁGINAS DO CINEMA E A NARRATIVA DO SUJEITO}

Mudanças significativas aconteceram na sociedade desde o surgimento do cinema no final do século XIX e, principalmente, no século XX: as revoluções industriais e as duas grandes guerras proporcionaram mudanças significativas relacionadas à formação e identidade do sujeito como um ser dotado de sentido e significado.

Assim, usar o cinema e as mudanças que foram proporcionadas através dos conflitos do século XX é, sem sobra de dúvidas, estudar as transformações ocorridas na sociedade através dessa arte. Tais mudanças, que abrangem da política à economia, logo perpassam por aspectos da sociedade que foram percebidas pelas diversas esferas sociais:

Os últimos trinta ou quarenta anos foram os mais revoltosos da história. O mundo, ou seja, a vida dos homens e mulheres que vivem na terra, nunca foi transformada de maneira tão profunda, dramática e extraordinária dentro de um período de tempo tão curto. As gerações que não viram o mundo antes têm dificuldades em perceber isso intuitivamente (HOBSBAWM, 1995, p. 107) 


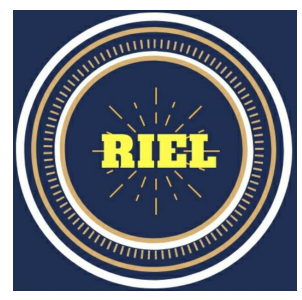

O fato é que "a evidência parece ser clara: o cinema é o meio de comunicação que mais atraiu pessoas desde seu surgimento" (DERING, FILETTI, 2013, p. 248) Desse modo, compreender o sujeito em seus contextos e suas formas de presentificação torna-se importante, uma vez que ele é parte preponderante desse tempo-espaço.

Logo, "Percebendo essas nuanças históricas, o audiovisual é o tipo de narrativa que mais torna visível essas mudanças, principalmente por se tratar de uma mídia, hoje em dia, de fácil acesso" (ANDRADE; DERING, 2013, p. 211). Olhar o sujeito, por assim ser, é perceber mudanças de cunho social e cultural, pois a ruptura que se compreende através do comportamento, da forma de se vestir ou falar, pode influenciar diretamente uma sociedade de tal modo, que pessoas pertencentes a uma mesma cultura acabam vivendo e alterando conjunturas e códigos de condutas para que possam viver em harmonia consigo e com o meio.

Exercendo a produção cinematográfica uma força direta com o seu receptor, ela faz parte de tais conjecturas propostas, pontuando que o sujeito pode sair do seu estado de inércia e ter poder de reflexão e ação social. Nesse sentido, ver e interpretar filmes implica acima de tudo, perceber o significado que eles têm no contexto social do qual participam (DUARTE, 2009) e, desse modo, agir sobre o mundo.

Sobre a percepção de significados, Almeida (1999) aponta que "Interpretar um filme somente pela mensagem explícita, visível ou dedutível pela história narrada é também uma interpretação incompleta, um naturalismo científico, mesmo que essa interpretação venha fundamentada em teorias estéticas, sociológicas e políticas.” Logo, essa ação implica sempre uma reação, por isso que, para Ferro (2010), o elemento não visível do cinema representa pensar a imagem além da superficialidade e em sua relação com o contexto sócio histórico da narrativa e do sujeito. Assim, a significação não fica restrita ao estudo cinematográfico superficial ou de contextos induzidos, mas fundamenta-se enquanto processo imagético e de abordagem ampla.

É preciso perceber que elementos presente na obra alteram o enredo/ narrativa, e por assim ser, tornam-se influenciadores para a interpretação fílmica. Por perceber esses envoltos, a reflexão sobre a posição do sujeito no mundo se amplifica. Nessa perspectiva, a questão sobre cinema, 
história, identidade e educação andam juntas e tem muito a contribuir com a valorização da cultura de uma sociedade.

Toma-se, inicialmente que, atentando-se às possibilidades do cinema enquanto ferramenta educativa e processo artístico de fomento à construção do sujeito, o cinema, arte sociocultural tão próxima dos sujeitos, deveria fazer parte dos currículos escolares, visto suas inúmeras prerrogativas de trabalho na formação do sujeito. Levantamos tal importância por perceber e entender o cinema como parte inerente da evolução da humanidade e fonte rica de promoção de saberes.

Contudo, é importante ressaltar que essa arte não pode ser secundarizada para utilização apenas como lacunas menores do processo de ensino-aprendizagem. Ocorre, pois, que "embora o cinema seja valorizado pela sociedade como arte, dentro das salas de aula existe uma barreira a ser quebrada, pois o cinema ainda é visto como mero entretenimento e não provedor de conhecimentos e aprendizagens.” (SANTOS; DERING, 2018, p. 277). Tem-se ainda que:

A inserção do cinema nas escolas ainda é encarada de forma a passar tempo, cobrir lacunas em salas de aula. No entanto, pode-se buscar novas perspectivas, como sua capacidade de despertar nos educandos a imaginação e criatividade, bem como suas relações sociais entre conhecimento escolar e prático (SANTOS; DERING, 2018, p. 270).

Logo, é preciso ir além, a arte cinematográfica deve ser parte integrante da formação escolar e de identidade do sujeito. O que deve ser refletido é que o cinema tem um valor mais do que mera representação ou de "preenchimento" de lacunas da escola, pois através dele, percebemos os costumes, o desenvolvimento da ciência, e a própria inovação dentro do discurso cinematográfico, valorizando a imagem como parte integrante no processo de aprendizagem.

A imagem e a visualidade constituem uma temática recorrente em variados domínios das ciências sociais, pois a comunicação visual e uma das mais antigas formas de comunhão coletiva, revelando ainda hoje fundamental na união como os outros (CAMPOS, 2013, p. 24).

Uma vez que se compreende que a educação vai além da sala de aula, podemos pensar o cinema como algo de integralização social, a qual os indivíduos pertencem aos mesmos códigos e costumes vividos na sociedade. Deste modo, é preciso entender que "Aprender arte é se 
autoconhecer, logo, criar identidade" (SANTOS; DERING, 2018, p. 279). Por assim ser, o cinema propõe narrativas as quais devemos (nos) perceber.

\section{A HISTÓRIA DE UM PALHAÇO}

O filme O Palhaço (2011), de Selton Mello, narra a história de uma trupe circense que está sempre na estrada para as suas apresentações com o Circo Esperança. Tem como protagonista Benjamim, que nas apresentações se transforma no palhaço Pangaré. A personagem é interpretada por Selton Mello e, na narrativa fílmica, é responsável pela organização do circo e dos procedimentos técnicos, sendo respeitado e amado por todos que fazem parte da trupe. É uma pessoa que cria admirações, mas não se admira; sente-se infeliz e solitário.

A atmosfera que circunda a personagem busca sempre mostrar sua desilusão consigo, apontando que ele parece estar perdido em seu próprio mundo e precisa de se encontrar como/ enquanto sujeito. A rotina do trabalho entre uma cidade e outra, o pouco dinheiro, a falta de um verdadeiro amor em sua vida e pela profissão que exige que ele faça com que os outros riam se faz questionar sobre o "quem eu sou?". Nesse questionamento, ele não percebe a si e as alegrias que vive e proporciona, tornando-se um palhaço triste e sem objetivos para si. "Portanto, a totalidade das linguagens e das ações simbólicas próprias de uma comunidade constitui sua cultura" (CHARTIER, 2010, p. 35). Esse momento, que se repete na obra em diversos pontos que podem ser tomados como uma sequência de epifanias dos sujeitos.

O termo "epifania" é usado no campo da narrativa para se referir a esses momentos, aparentemente comum e insignificantes, nos quais ou o indivíduo experimenta uma impressão repentina e fugaz, mas intensamente comovente, que provoca nele uma compreensão intuitiva de um sentido transcendente 3 (GONZÁLES; GROSSO, 2013, p. 61, tradução nossa).

Assim, suas epifanias aparecem entre viagens, apresentações e inquietações da alma. É nesse percurso de questionamento sobre si que Benjamim se apaixona por uma moça de outro município,

\footnotetext{
3 “El término 'epifanía' se emplea en el campo de la narrativa para aludir a aquellos momentos, en aparecia corrientes e insignificantes, en los que o individuo experimenta una impresión súbita y fugaz pero intensamente conmovedora, que provoca en él una comprensión intuitiva de un sentido trascendente" (GONZÁLES; GROSSO, 2013, p. 61)
} 


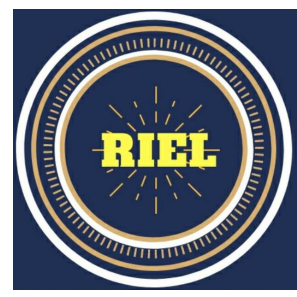

Ana. É a partir desse momento que percebe-se a busca da identidade, quando surge uma vontade, por parte do protagonista, de tentar encontrar um amor e "ser normal".

As identidades parecem invocar uma origem que residiria em um passado histórico com o qual elas continuariam a manter uma certa correspondência. Elas têm a ver, entretanto, com a questão da utilização dos recursos da história, da linguagem da cultura para a produção não daquilo que nós somos, mas daquilo no qual nos tornamos. Têm a ver não tanto com as questões "quem nós somos" ou "de onde nós viemos", mas muito mais com as questões "quem nós podemos nos tornar", "como nós temos sido representados" e "como essa representação afeta a forma como nós podemos representar a nós próprios (HALL, 2008, p. 108-109).

Essa busca do sujeito em encontrar o seu eu, na modernidade é algo que perpassa as excessivas possibilidades que o mundo propõe. Logo, é importante ressaltar que "em nossa sociedade o problema da identidade tem se intensificado de forma intrigante. Vivemos em um mundo repleto de alternativas que inibem ou omitem nossas fraquezas com relação ao outro.” (MONTES, 2012, p. 164). Será entre essas possibilidades que Benjamin começa a se questionar sobre quem é.

Entre a monotonia e a desilusão, há elementos simbólicos na obra que dita o rumo das discussões, são eles o ventilador e a identidade, elementos que se entrecruzam na proposta da narrativa promovendo significados. Dessa forma, tomamos que "o significado é inerentemente instável: ele procura o fechamento (a identidade), mas ele é constantemente perturbado (pela diferença)" (HALL, 2005, p. 41). Por assim ser, é preciso, compreender que imagens são mensagens e estas configuram-se por elementos da narrativa.

Daí a importância de interpretarmos as imagens do cinema e da televisão, e não somente as "populares", como expressões alegóricas do momento de sua produção e exibição. Alegorias em movimento. Eternizam-se a cada instante em que permanecem visíveis e enquanto resistem à deterioração e às restaurações. Alegorias do tempo presente e da história repassada nesse tempo presente (ALMEIDA, 1999, p. 13).

Por assim ser, a identidade pode ser interpretada de duas formas: a física (documento chamado de Registro Geral, emitido pelos Estados e presente na obra como a "criação da 
identidade") e a outra é a identidade do próprio sujeito, que é a compra do ventilador, que pode ser interpretado como um sonho almejado pelo sujeito ao ter uma "identidade física".

Como linguagem rica e sensorialmente composta, o cinema, enquanto meio de comunicação, está aberto a todos os tipos de simbolismos e energias literárias e imagística, a todas as representações coletivas, correntes ideológicas, tendência estética e ao infinito jogo de influências no cinema, nas outras artes e na cultura de modo geral (STAM, 2008, p. 24).

É interessante perceber que criação do documento de identidade cria a possibilidade de realização de um sonho do sujeito, comprar um ventilador. Contudo, essa visão de "quem eu sou?" se mistura à do documento físico de identidade, trazendo o simbolismo da linguagem, bem como dialogando com a proposição das identidades nacionais. Nesse ponto, Hall (2005, p. 48) aponta que “As identidades nacionais não são coisas com as quais nascemos, mas são formadas e transformadas no interior da representação". Isso cria sua confusão consigo e com o mundo.

Logo, no meio da desordem interna e os conflitos externos, Benjamim diz estar cansado da vida que tem e que precisa resolvê-la. Seu questionamento que justifica todo o desenrolar da narrativa é: “Eu faço o povo rir, mas quem é que vai me fazer rir?” (48':22, MELLO, 2011). Desse modo, ele sai da trupe para se reencontrar e vai a procura da jovem Ana que, por ventura, já está comprometida com outro rapaz. Tem sua primeira desilusão com a identidade de "Benjamin" em seu documento. Esse primeiro momento deixa claro a fragilidade das identidades dos sujeitos, o que acontece com o protagonista. Logo, "a fragilidade e a condição eternamente provisória da identidade não podem mais ser ocultadas.” (BAUMAN, 2005, p. 22).

Assim, mesmo com a desilusão, ele tenta se adaptar na cidade, com a rotina de sua nova identidade; arruma um emprego e, finalmente, compra um ventilador, objeto que está presente em todo o filme como um desejo um sonho e até mesmo uma obsessão. O ventilador, então, é algo extremamente simbólico, por ser um elemento intensificador da narrativa, sendo possível fazer diversas interpretações, inclusive a ideia de pertencimento ao mundo. Sobre o assunto, Bauman (2005) pontua que identidade e pertencimento não tem solidez por toda a vida, podendo ser alterados de acordo com contextos e pela própria relação do sujeito com esses contextos, visto que 
as "decisões que o próprio indivíduo toma, os caminhos que percorre, a maneira como age” (BAUMAN, 2005, p. 17) influenciam sua identidade.

Em suma, a narrativa mostra que Benjamim deseja ter um ventilador, mas não tem uma identidade (documento) para comprar o tão sonhado ventilador (bem como não pode comprá-lo à vista, pois não tem dinheiro suficiente para a tal compra, precisando fazer um crediário, que só pode ser feito com um documento de identidade, que não tem). O ventilador simboliza novos ares e novas direções, o documento de identidade, a possível resposta do “quem sou eu?”, mas uma não coincide com a outra, como ele vai perceber depois. Isso ocorre visto que:

É precisamente porque as identidades são construídas dentro e não fora do discurso que nós precisamos compreendê-las como produzidas em locais históricos e institucionais específicos, no interior de formações e práticas discursivas específicas, por estratégias e iniciativas específicas (HALL, 2008, p. 109).

Logo, a desilusão amorosa, o trabalho desinteressante e a percepção de suas identidades são fatores primordiais para seu reencontro. Quando o Benjamim resolve voltar para o Circo Esperança, já percebemos que o sujeito, ali, encontrou-se, visto sua afirmação, reprodução da frase de seu pai: “O gato bebe leite, o rato como queijo, e eu sou um palhaço”. (74'11”, MELLO, 2011).

\section{CONSIDERAÇÕES FINAIS}

Portanto, como processo de formação do senso crítico, fica pressuposto que o primeiro ponto é valorizar o cinema como sendo responsável por uma formação e construção de identidade do sujeito diferenciada, pois ele deixa de ser um simples evento de diversão para se tornar fundamental na criticidade dos sujeitos. Uma vez que "os filmes são, portanto, produzidos e vistos dentro de um contexto social e cultural, por meio de suas narrativas, que vai além do prazer da história” (TURNER, 1997, p. 69).

A facilidade de acesso ao cinema é outro fator importante para que seu uso na formação do sujeito seja constante, sendo fonte enriquecedora para externalizar problemas sociais e individuais, como questões de identidade. Nesse sentido, na obra fílmica analisada, pudemos perceber que 
embora o sujeito tenha saído do seu grupo familiar por um conflito da busca de quem ele era ou tentava ser, ele acaba se encontrando após uma intersecção consigo e com o mundo, percebendo sua história e sua cultura, bem como sua relação com ambas. Mais do que isso, também se aceita como um artista circense.

O protagonista, então, que saiu em busca de encontrar respostas para as questões da vida e suas próprias dúvidas sobre si, acaba perfazendo diálogos intermitentes na busca de sua identidade. Desse modo:

[...] é impossível pensar o discurso sem focalizar os sujeitos envolvidos em um contexto de produção: todo discurso provém de alguém que tem suas marcas identitárias específicas que o localizam na vida social e que o posicionam no discurso de um modo singular assim como seus interlocutores (MOITA LOPES, 2003, p. 19).

Por assim ser, podemos compreender e refletir que os discursos que perfazem o sujeito promovem identidades que vão se construindo na relação entre sujeitos e discursos. Ao analisar o filme O palhaço (2011) e a narrativa cinematográfica, portanto, percebemos como a arte pode ser utilizada como fonte problematizadora, possibilitando a construção do senso crítico, principalmente no que se refere às discussões identitárias.

\section{REFERÊNCIAS}

ALMEIDA, M. J. A educação visual da memória: imagens agentes do cinema e da televisão. ProPosições. v.10, n. 2 (29), jul/1999.

ANDRADE, V. S; DERING, R. O. Perspectivas de História e ficção: uma leitura do filme as Melhores coisas do mundo. Revista Litteris, n.11, mar/jun, 2013.

BAUMAN, Z. Identidade: entrevista a Benedetto Vecchi. Rio de Janeiro: Jorge Zahar, 2005

CAMPOS, R. Imagem e tecnologia visual em pesquisa social: tendências e desafios. In MARTINS, R.; TOURINHO, I. (Orgs.). Processo e práticas de pesquisa em cultura visual e educação. Santa Maria: Editora da UFSM, 2013.

CARRIÉRE, J. C. A linguagem secreta do cinema. Rio de Janeiro: Nova Fronteira, 2015.

CHARTIER, R. A história ou a leitura do tempo. Trad. Cristina. Antunes. Belo Horizonte: Autêntica Editora, 2010. 
DERING, R. O.; FILETTI, E. As novas mídias e as práticas educativas: literatura e cinema em ambiente escolar. Revista de Letras da UNIABEU, Nilópolis, v.4, n.2, 2013, pp. 246-257.

DUARTE, R. Cinema e educação. Belo Horizonte: Autêntica, 2009.

FERRO, M. Cinema e História. São Paulo: Paz e Terra, 2010.

GONZÁLES, M. I.; GROSSO, M. Instrumentos de la crítica narrativa: una introducción al análisis de textos literarios. Buenos Aires: Colihue, 2013.

HALL, S. Identidade cultural na pós-modernidade. São Paulo: Empório do Livro, 2005.

. Quem precisa da identidade? In: SILVA, T. T. (Org.) Identidade e diferença: a perspectiva dos estudos culturais. Petrópolis/RJ: Vozes, 2008.

HOBSBAWM, E. J: Era dos extremos: o breve século XX. São Paulo: Cia Letras, 1999.

MELLO, S. O palhaço. Direção: Selton Mello. Produção: Vania Catani Bananeira Filmes. Roteiro: Selton Mello e Marcelo Vindicatto. Rio de Janeiro: Globo Filmes. 1 DVD (90 min), Widescreen, Color. Produzido por Globo Filmes, Distribuído por Imagem Filmes. 2011.

MOITA-LOPES, L. P. Socioconstrucionismo: discurso e identidades sociais. In: MOITA-LOPES, L. P. (Org.) Discursos de identidades: discurso como espaço de construção de gênero, sexualidade, raça, idade e profissão na escola e na família. Campinas, SP: Mercado das Letras, 2003.

MONTES, S. S. A identidade do sujeito na pós-modernidade: algumas reflexões. Revista Fórum Identidades. Itabaiana, ano 6, v. 12, jul/dez, 2012, pp.162-167.

SANTOS; G. C.; DERING, R. O. O cinema como produtor de conhecimento em sala de aula. In. SKRSYPCSAK, D.; SCHÜTZ, J. A. Debates contemporâneos em educação. São Paulo: Dialogar, 2018.

STAM, R. A literatura através do cinema: realismo, magia e a arte da adaptação. Trad. MarieAnne Kremer e Glaucia Renato Gonçalves. Belo Horizonte: UFMG, 2008.

TURNER, G. Cinema como prática social. São Paulo: Summus, 1997. 